\title{
Influence of Whitening Gel Application Protocol on Dental Color Change
}

\author{
Taciana Marco Ferraz Caneppele, Carlos Rocha Gomes Torres, \\ Maria Filomena Rocha Lima Huhtala, and Eduardo Bresciani
}

Department of Restorative Dentistry, Institute of Science and Technology, Universidade Estadual Paulista (UNESP), Avenue Francisco José Longo 777, 12245-000 São José dos Campos, SP, Brazil

Correspondence should be addressed to Taciana Marco Ferraz Caneppele; taciana@fosjc.unesp.br

Received 3 February 2015; Accepted 24 February 2015

Academic Editor: Cornelis H. Pameijer

Copyright (C) 2015 Taciana Marco Ferraz Caneppele et al. This is an open access article distributed under the Creative Commons Attribution License, which permits unrestricted use, distribution, and reproduction in any medium, provided the original work is properly cited.

\begin{abstract}
Objectives. To evaluate the influence of different whitening protocols on the efficacy of $35 \%$ hydrogen peroxide (HP) tooth whitening and gel $\mathrm{pH}$ and concentration. Material and Methods. Eighty-four enamel/dentin discs from bovine incisors were used. The baseline color was measured with a spectrophotometer. Two sessions of in-office whitening with $35 \% \mathrm{HP}$ were performed under different protocols: G1: 3 applications of HP (10 min each) per session; G2: 1 application of 30 min per session; G3: 1 application of 40 min per session, with no gel replenishment within session for groups 2 and 3. HP titration and $\mathrm{pH}$ evaluation at baseline, after 10, 30, and $40 \mathrm{~min}$ were also performed. The final color was measured $24 \mathrm{~h}$ after the 1 st and 2 nd whitening sessions. Data were submitted to Repeated Measures ANOVA and Tukey's test. Results. For color evaluation, no differences were observed among groups after two sessions. HP titration showed no drop on concentration after 10, 30, or $40 \mathrm{~min}$. The $\mathrm{pH}$ was 5.54 at baseline and 5.41 after $40 \mathrm{~min}$. Conclusion. Replenishment or extended application time of in-office whitening gel does not affect gel $\mathrm{pH}$ and concentration, a fact that supports the similar effectiveness of whitening observed among the tested protocols.
\end{abstract}

\section{Introduction}

Tooth whitening offers a conservative, simplified, and economical alternative to modify the color of teeth. Currently, three main approaches are adopted for vital tooth whitening, which are at-home, in-office, and over-the-counter whitening therapies [1].

Several studies have been conducted to evaluate the efficacy of different products and protocols [2-4] for tooth whitening, and the results are usually conflicting. Three factors present noticeable influence on the activity of whitening agents, which are often involved in the kinetics of most chemical reactions. They are heat, concentration, and $\mathrm{pH}$ [5]. Regarding heating, all whitening agents act faster with increasing temperature. Heat accelerates the permeation of hydrogen peroxide into enamel and its action on stained substance [6]. However, heat may be hazardous to pulp cells, once it might aggravate pulp damage in contact to hydrogen peroxide [7]. Regarding gel concentration, the presence of greater number of reactive molecules generally leads to increased activity, although the response performance at higher concentrations is not necessarily linear for whitening products. With respect to $\mathrm{pH}$, alkalinity accelerates the decomposition of hydrogen peroxide. Thus, some whitening products are presented in two bottles, one with hydrogen peroxide solution in acidic $\mathrm{pH}$ (stable) and another with alkaline $\mathrm{pH}$. When solutions are mixed, the $\mathrm{pH}$ becomes neutral, resulting in degradation/activity of hydrogen peroxide. Over time, with the degradation of hydrogen peroxide, the $\mathrm{pH}$ would become acidic, decreasing the effectiveness of peroxide action and possibly leading to damage to tooth structure. This last finding would support the rationale for replenishing the whitening gel during in-office whitening therapies.

According to some manufacturers' instructions, during in-office whitening, highly concentrated hydrogen peroxide whitening gel is left on tooth surface for 5 to 20 minutes and replenished 2 or 3 times. However, a certain amount of time is necessary for the hydrogen peroxide to act on enamel [8] and 
the decomposition of hydrogen peroxide requires a certain period of time when no activator is used.

However, the effect of different in-office whitening protocols on the $\mathrm{pH}$ and concentration of the gel during the treatment has not been investigated. Thus, the aim of this study was to evaluate the gel $\mathrm{pH}$ and concentration, and the efficacy of 35\% hydrogen peroxide (HP) tooth whitening with different application times using enamel/dentin substrate.

\section{Material and Methods}

2.1. Color Measurement. The specimens were prepared according to the method described by Wiegand et al. [9]. Eighty-four extracted, nondamaged, and intact bovine incisors were used. The teeth were obtained from a local slaughterhouse. Enamel-dentin specimens presenting $3 \mathrm{~mm}$ in diameter and $2 \mathrm{~mm}$ in height $(1 \mathrm{~mm}$ of enamel and $1 \mathrm{~mm}$ of dentin) were prepared from the buccal surface using a trephine mill. Prior to treatment, the baseline color of each specimen was assessed under standardized ambient conditions according to the CIE $L^{*} a^{*} b^{*}$ system, using a spectrophotometer (CM2600d, Konica Minolta). The device was adjusted to use the D65 standard light source with $100 \%$ UV included or $100 \%$ UV excluded and specular reflection included (SCI). The observer angle was set at $2^{\circ}$ and the device was adjusted to a small reading area (SAV). The color of each sample was assessed 3 times and averaged. The results of color measurements were quantified in terms of three coordinate values $\left(L^{*}, a^{*}, b^{*}\right)$, as established by the Commission Internationale de l'Eclariage (CIE), which locates the color of an object in a three-dimensional color space. Axis $L^{*}$ represents the degree of lightness within a sample and ranges from 0 (black) to 100 (white). Axis $a^{*}$ represents the degree of green/red color, while $b^{*}$ axis represents the degree of blue/yellow color within the sample. The $L^{*}$ value of each specimen was used for stratified allocation among 3 groups. The color was measured over white ( $L: 84.95 ; a:-0.38 ; b: 2.93)$ standard backgrounds. From the color measurement at baseline and those after the whitening procedures, the values of the changes of $L^{*}(\Delta L)$, $a^{*}(\Delta a)$, and $b^{*}(\Delta b)$ were calculated. Next, the total change color or the variation in perception of color of each specimen was calculated, designated by the abbreviation $\triangle E a b$. This parameter was calculated according to the following formula:

$$
\Delta E * a b=\left(\Delta L^{2}+\Delta a^{2}+\Delta b^{2}\right)^{1 / 2}
$$

2.2. Whitening Procedure. An experimental 35\% HP gel, composed of two components, was used. The first component was a solution of $50 \%$ hydrogen peroxide containing an acrylic thickener, which is a white solution in an acidic environment (solution $\mathrm{A}-\mathrm{pH}$ 1.5). The second component was an aqueous solution containing an alkaline substance (solution $\mathrm{B}-\mathrm{pH} 11.3$ ). In order to produce the final whitening gel ( $\mathrm{pH}$ 6.5) three parts of solution A and one part of solution $\mathrm{B}$, by volume, were mixed.
Once mixed, a $2 \mathrm{~mm}$ thick layer (approximately $0.1 \mathrm{~g}$ ) of the whitening gel was applied over the surface of the specimens.

Three different protocols of application were performed.

Group 1, $3 \times 10$ : the gel was allowed to remain on specimens' surface for $10 \mathrm{~min}$, with gentle stirring after $5 \mathrm{~min}$ using a plastic instrument to dislodge the bubbles formed. After ten minutes, the gel was removed using a vacuum aspirator and two additional applications were performed, for a total of $30 \mathrm{~min}$ of active whitening.

Group 2, $1 \times 30$ : the gel was allowed to remain on specimens' surface for $30 \mathrm{~min}$, with gentle stirring each $5 \mathrm{~min}$ using a plastic instrument to dislodge the bubbles formed.

Group 3, $1 \times 40$ : the gel was allowed to remain on specimens' surface for $40 \mathrm{~min}$, with gentle stirring each $5 \mathrm{~min}$ using a plastic instrument to dislodge the bubbles formed.

All specimens were stored in artificial saliva for 7 days and the whitening procedure was repeated. The color measurements were performed after the specimens were stored in artificial saliva for $24 \mathrm{~h}$ (after first and second whitening sessions).

2.3. $p H$ Evaluation. Gel $\mathrm{pH}$ was measured using a portable pH meter (Seven Multi, Mettler Toledo Inc., Canton, MA, USA) with a direct electrode, which was calibrated with standard buffer solutions at $\mathrm{pH} 4.0$ and 6.86 prior to analysis. The $\mathrm{pH}$ was assessed at baseline and after 10, 30, and $40 \mathrm{~min}$. Additional five teeth were used, at each the periods described above, to allow the collection of certain volume of hydrogen peroxide for $\mathrm{pH}$ measurement. Five measurements per period were performed and the mean was calculated.

2.4. HP Titration. The titration method, using $0.1 \mathrm{~N}$ potassium permanganate solution, assessed the correct concentration of $\mathrm{H}_{2} \mathrm{O}_{2}$ from the pure $50 \mathrm{w} \% \mathrm{H}_{2} \mathrm{O}_{2}$ solution (SigmaAldrich, Buchs, Switzerland) used to prepare the gel, and also assessed HP concentration during the whitening process. Primary standard sodium oxalate was used to standardize the $0.1 \mathrm{~N} \mathrm{KMnO}_{4}$ solution [10].

A $2 \mathrm{~mm}$ layer of whitening gel was applied over five additional bovine incisors and collected after 10, 30, and $40 \mathrm{~min}$ of service, for titration analysis. Five titrations for each evaluated time were performed and the HP mean concentration was calculated.

Figure 1 presents the study design.

2.5. Statistical Analysis. Obtained data were statistically analyzed using Statistica for Windows (Statsoft). Repeated measures analysis of variance and Tukey's test were applied at a significant level of 0.05 for color, $\mathrm{pH}$, and concentration evaluation.

\section{Results}

3.1. Whitening Efficacy. The overall color coordinates measurements are shown in Table 1.

For color changes, based on repeated measures ANOVA, there were significant differences between the whitening 


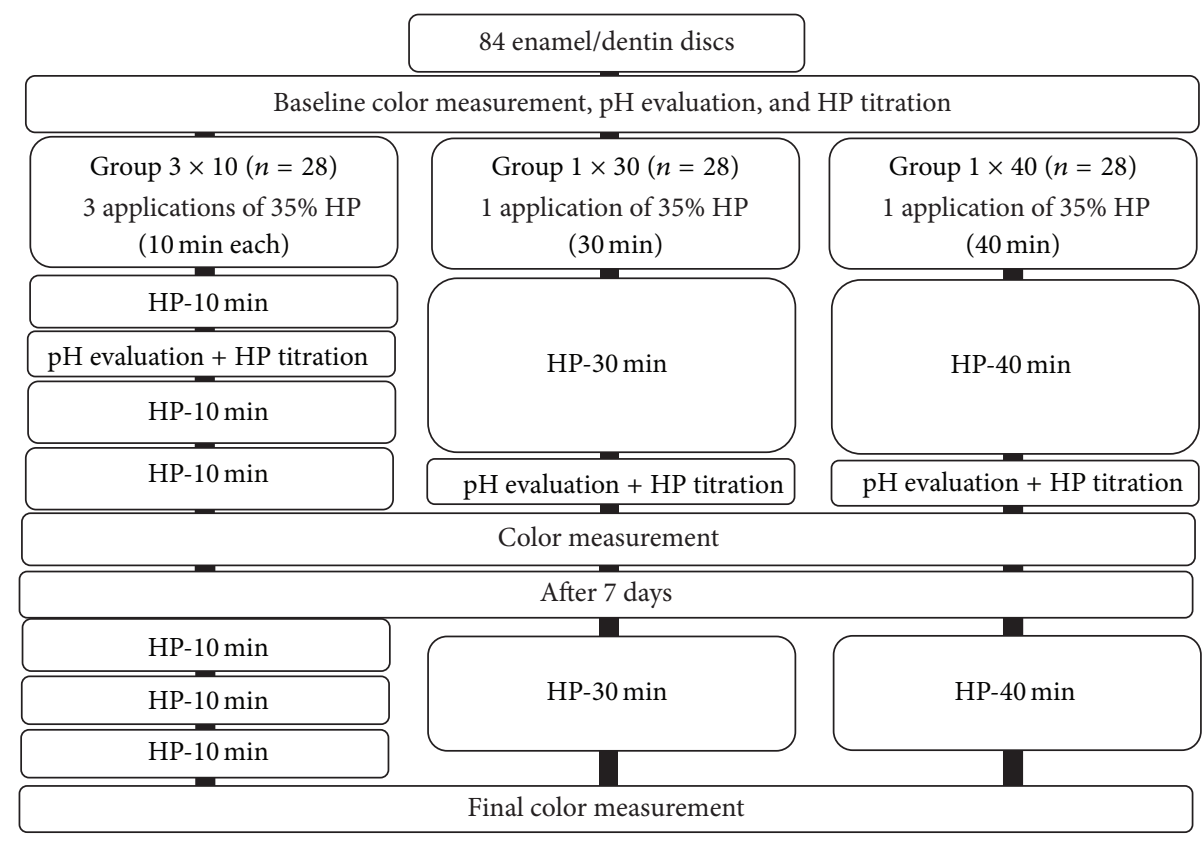

FIGURE 1: Schematic representation of the design of the study.

TABLE 1: Mean and standard deviations of color parameters for all experimental conditions.

\begin{tabular}{|c|c|c|c|c|c|c|c|c|}
\hline & \multicolumn{2}{|c|}{$\Delta L$} & \multicolumn{2}{|c|}{$\Delta a$} & \multicolumn{2}{|c|}{$\Delta b$} & \multicolumn{2}{|c|}{$\Delta E$} \\
\hline & 1 session & 2 sessions & 1 session & 2 sessions & 1 session & 2 sessions & 1 session & 2 sessions \\
\hline $3 \times 10 \mathrm{~min}$ & $-0.60 \pm 2.74$ & $-0.50 \pm 2.14$ & $0.96 \pm 0.53$ & $0.48 \pm 0.36$ & $-3.00 \pm 1.15$ & $-4.73 \pm 1.02$ & $4.19 \pm 1.24$ & $5.24 \pm 1.00$ \\
\hline $1 \times 30 \mathrm{~min}$ & $-1.07 \pm 1.88$ & $-1.30 \pm 1.86$ & $1.17 \pm 0.56$ & $0.81 \pm 0.49$ & $-2.82 \pm 1.03$ & $-4.52 \pm 0.86$ & $3.78 \pm 0.96$ & $5.14 \pm 0.82$ \\
\hline $1 \times 40 \mathrm{~min}$ & $-1.11 \pm 2.55$ & $-1.11 \pm 2.06$ & $1.41 \pm 0.62$ & $0.70 \pm 0.65$ & $-3.27 \pm 1.26$ & $-5.19 \pm 1.15$ & $4.53 \pm 1.27$ & $5.77 \pm 1.08$ \\
\hline
\end{tabular}

sessions $(P<0.05)$, but no differences were found between the different protocols $(P>0.05)$.

Figure 2 shows the results of $\Delta b$ and $\Delta E a b$. After two sessions, for all experimental conditions there was an increase of color change.

3.2. HP Concentration and $p H$ Evaluation. For HP titration, no statistical difference was observed at baseline and during the periods of evaluation $(P>0.05)$. Also for $\mathrm{pH}$ evaluation, although a small drop on $\mathrm{pH}$ was observed during the treatment time, it was not statistically significant $(P>0.05)$. Figure 3 shows the results for both analyses.

\section{Discussion}

This study compared different protocols of in-office whitening regarding efficacy (color change), $\mathrm{pH}$, and concentration of HP.

Previous studies have evaluated the outcomes of tooth whitening using the $\triangle E a b$ formula. However, there is no consensus on which of the parameters $(\Delta L, \Delta a, \Delta b$, or $\Delta E a b)$ would be best suitable to predict adequate whitening results. Li [11] reported that the most critical challenge in the evaluation of color with spectrophotometers and colorimeters is the lack of methods for interpreting data from instruments in relation to clinical changes of dental color. Bengel [12] observed that major changes occur in the values of $L^{*}$ and $b^{*}$ coordinates after whitening, and the coordinate $b^{*}$ would be more relevant in assessing the whitening treatment. For that author, $\Delta E a b$ does not reflect the total color change. Karpinia et al. [13] observed a significant reduction of yellowing $(\Delta b)$ and an increased lightness $(\Delta L)$ after whitening procedures. In the present study, the greatest differences before and after whitening were observed for the $b^{*}$ coordinate (Table 1 , Figure 2(a)).

For all groups, after the second session, there was an increase on the degree of whitening and it may be observed by the increase of $\Delta b$ and $\Delta E a b$ (Table 1 and Figure 2).

Tooth enamel is the densest tissue in the human body and has a very low permeability. Therefore, the permeation of hydrogen peroxide is slow [14]. Because a certain amount of time is necessary for the hydrogen peroxide to act on enamel [8], and as the decomposition of hydrogen peroxide takes place a long period of the time, it was tested the prolonged application time of peroxide without replenishing of the gel. The results of this study showed that replenishing the gel every $10 \mathrm{~min}$ for 3 times per section (as recommended by some manufacturers) did not affect the efficacy of treatment. In agreement with this research, Al-Harbi et al. [15] also 

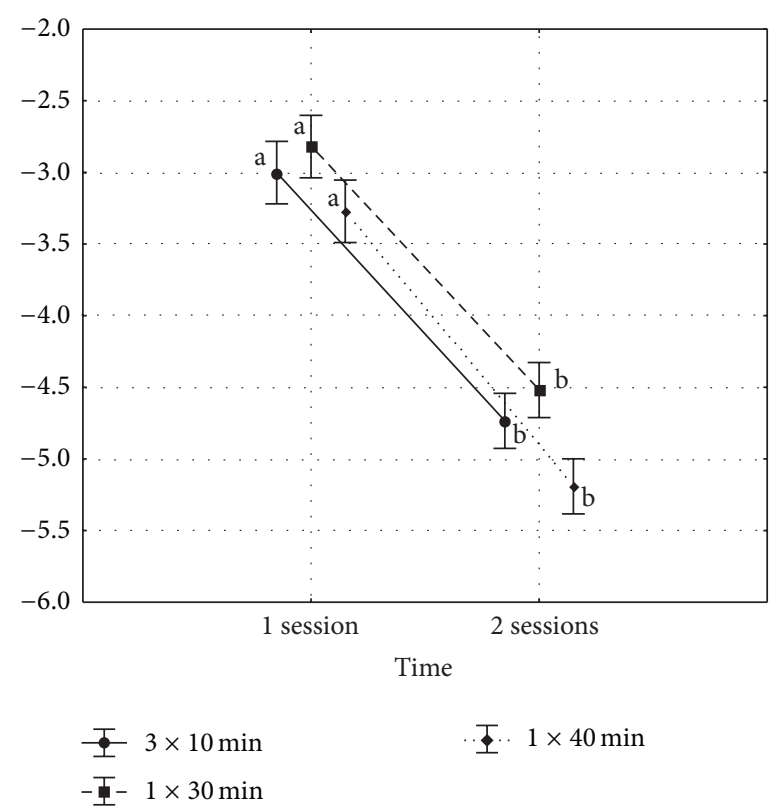

(a)

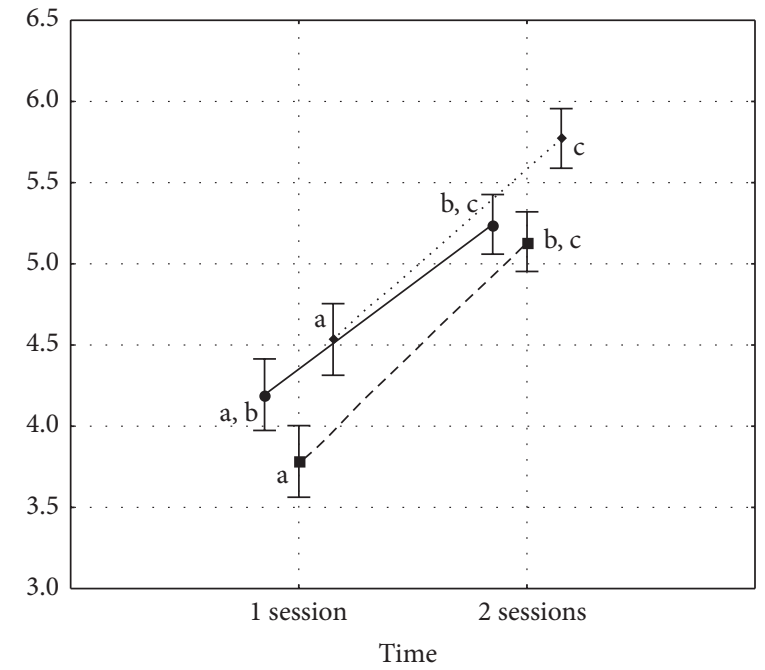

ఫ- $3 \times 10 \mathrm{~min}$
-포- $1 \times 30 \mathrm{~min}$

(b)

FIGURE 2: Results of $\Delta b$ (a) and $\Delta E a b$ (b). Vertical bars denote \pm standard errors, and sets with the same letters are not significantly different (Tukey's Test, $P>0.05$ ).

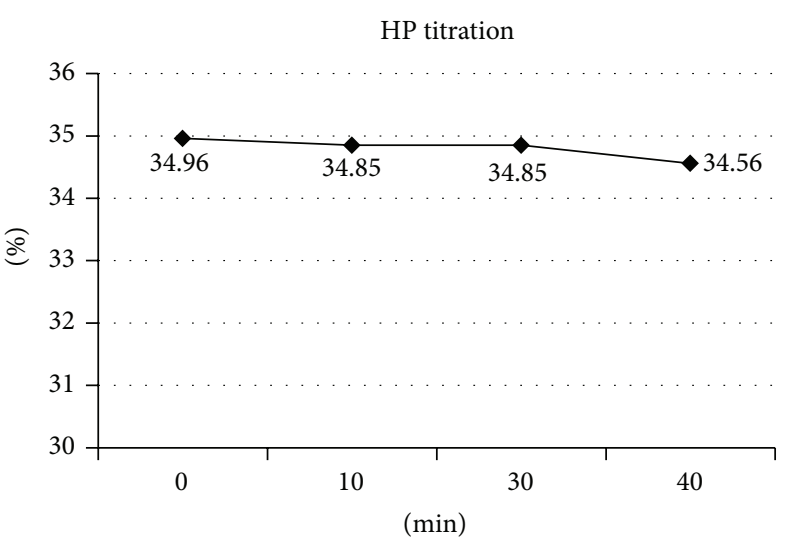

(a)

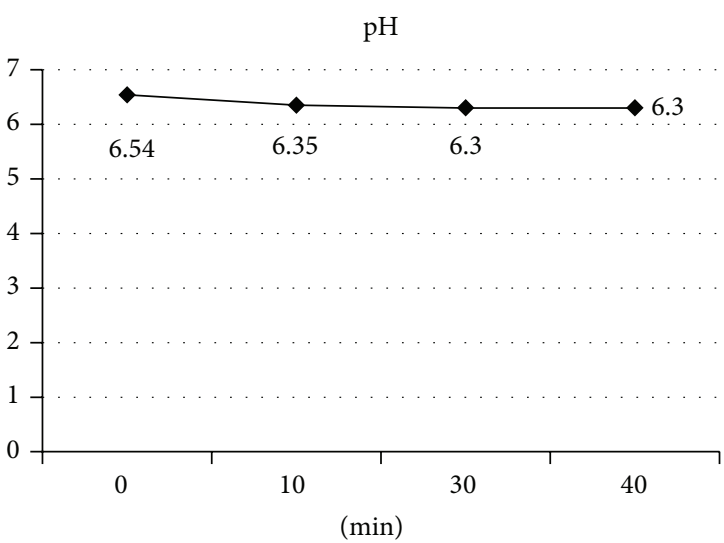

(b)

Figure 3: HP titration (a) and $\mathrm{pH}$ evaluation (b).

observed no significant difference in the effectiveness of treatment when performed 2 applications of $30 \mathrm{~min}$ or 4 of $15 \mathrm{~min}$. Similar results were obtained in an in vitro study carried by Kwon et al. [16]. The authors also found that there was significantly greater hydrogen peroxide penetration in the pulp when the gel was replenished during the treatment. However, Reis et al. [17] observed an increase of tooth sensitivity levels when prolonged application time of hydrogen peroxide was performed.

The extended time of 40 min was not able to significantly increase the whitening efficacy. Further studies should be carried to verify from that point the increase of application time could affect the efficacy of the treatment.
The present whitening efficacy behavior might be associated to no changes on gel $\mathrm{pH}$ and concentration at different assessed periods.

After forty minutes of gel application a small decrease in HP concentration on tooth surface was detected (not significant). This result indicates that a small amount of peroxide was degraded. Free radicals derived from the HP decomposition are slowly formed without the presence of a potent catalyst. In the present study, an increase in $\mathrm{pH}$ acts as catalyst and was obtained by mixing the 2 solutions immediately prior to use. Fornaini et al. [18] also observed a small decrease in the HP concentration in whitening gel, after 20 minutes in contact with the tooth structure. Thus, 
the rationale of replenishment of gel every 10 min because of the rapid degradation of hydrogen peroxide is not valid.

One concern with the whitening treatment is the possibility of demineralization of tooth enamel. Some whitening gels have acidic $\mathrm{pH}$, which may favor this demineralization [19]. The neutral or basic pH of whitening agents might minimize changes in tooth structure and side effects such as tooth sensitivity and gingival irritation [20]. Also, according to Coons [5], alkaline $\mathrm{pH}$ accelerates the degradation of hydrogen peroxide by increasing the release of free radicals. Over time, with the degradation of hydrogen peroxide, the $\mathrm{pH}$ would become acidic, decreasing the efficacy of peroxide and also damaging the tooth structure. However, this study found that after $40 \mathrm{~min}$ a small, nonsignificant decrease in $\mathrm{pH}$ was observed, remaining at acceptable levels that are incapable of promoting enamel demineralization, and also reducing the degradation of the product.

\section{Conclusion}

Within the limitations of the present study it could be concluded that replenishment or extended time of application of in-office whitening gel does not affect the efficacy of the treatment and gel $\mathrm{pH}$ and concentration did not change during the $40 \mathrm{~min}$ of evaluation. All protocols were similar after one or two in-office sessions.

\section{Conflict of Interests}

The authors declare that they have no conflict of interests.

\section{Acknowledgment}

This investigation was supported in part by Research Grant 2012/10917-6 from FAPESP, São Paulo, Brazil.

\section{References}

[1] R. A. Basson, S. R. Grobler, T. J. Kotze, and Y. Osman, "Guidelines for the selection of tooth whitening products amongst those available on the market," Journal of the South African Dental Association, vol. 68, no. 3, pp. 122-129, 2013.

[2] T. M. Caneppele, A. B. Borges, and C. R. Torres, "Effects of dental bleaching on the color, translucency and fluorescence properties of enamel and dentin," The European Journal of Esthetic Dentistry, vol. 8, no. 2, pp. 200-212, 2013.

[3] B. J. Nutter, M. O. Sharif, A. B. Smith, and P. A. Brunton, "A clinical study comparing the efficacy of light activated insurgery whitening versus in-surgery whitening without light activation," Journal of Dentistry, vol. 41, supplement 5, pp. e3e7, 2013

[4] D. G. Soares, A. P. D. Ribeiro, F. da Silveira Vargas, J. Hebling, and C. A. de Souza Costa, "Efficacy and cytotoxicity of a bleaching gel after short application times on dental enamel," Clinical Oral Investigations, vol. 17, no. 8, pp. 1901-1909, 2013.

[5] D. M. Coons, "Bleach: facts, fantasy, and fundamentals," Journal of the American Oil Chemists' Society, vol. 55, no. 1, pp. 104-108, 1978.
[6] W. H. Bowles and L. R. Thompson, "Vital bleaching: the effects of heat and hydrogen peroxide on pulpal enzymes," Journal of Endodontics, vol. 12, no. 3, pp. 108-112, 1986.

[7] A. P. Dias Ribeiro, N. T. Sacono, F. C. R. Lessa et al., "Cytotoxic effect of a 35\% hydrogen peroxide bleaching gel on odontoblastlike MDPC-23 cells," Oral Surgery, Oral Medicine, Oral Pathology, Oral Radiology and Endodontology, vol. 108, no. 3, pp. 458464, 2009.

[8] J.-H. Chen, J.-W. Xu, and C.-X. Shing, "Decomposition rate of hydrogen peroxide bleaching agents under various chemical and physical conditions," The Journal of Prosthetic Dentistry, vol. 69, no. 1, pp. 46-48, 1993.

[9] A. Wiegand, D. Vollmer, M. Foitzik, R. Attin, and T. Attin, "Efficacy of different whitening modalities on bovine enamel and dentin," Clinical Oral Investigations, vol. 9, no. 2, pp. 91-97, 2005.

[10] P. K. Hardman, D. L. Moore, and G. H. Petteway, "Stability of hydrogen peroxide as a bleaching agent," General Dentistry, vol. 33, no. 2, pp. 121-122, 1985.

[11] Y. Li, "Tooth color measurement using chroma meter: techniques, advantages, and disadvantages," Journal of Esthetic and Restorative Dentistry, vol. 15, no. supplement 1, pp. S33-S41, 2003.

[12] W. M. Bengel, "Digital photography and the assessment of therapeutic results after bleaching procedures," Journal of Esthetic and Restorative Dentistry, vol. 15, supplement 1, pp. S21-S32, 2003.

[13] K. A. Karpinia, I. Magnusson, P. A. Sagel, X. Zhou, and R. W. Gerlach, "Vital bleaching with two at-home professional systems," The American Journal of Dentistry, vol. 15, pp. 13A18A, 2002.

[14] C. R. G. Torres, C. S. Souza, A. B. Borges, M. F. R. L. Huhtala, and T. M. F. Caneppele, "Influence of concentration and activation on hydrogen peroxide diffusion through dental tissues in vitro," The Scientific World Journal, vol. 2013, Article ID 193241, 5 pages, 2013.

[15] A. Al-Harbi, S. Ardu, T. Bortolotto, and I. Krejci, "Effect of extended application time on the efficacy of an in-office hydrogen peroxide bleaching agent: an in vitro study," The European Journal of Esthetic Dentistry, vol. 8, no. 2, pp. 226-236, 2013.

[16] S. R. Kwon, P. W. Wertz, D. V. Dawson, D. S. Cobb, and G. Denehy, "The relationship of hydrogen peroxide exposure protocol to bleaching efficacy," Operative Dentistry, vol. 38, no. 2, pp. 177-185, 2013.

[17] A. Reis, L. Y. Tay, D. R. Herrera, S. Kossatz, and A. D. Loguercio, "Clinical effects of prolonged application time of an in-office bleaching gel," Operative Dentistry, vol. 36, no. 6, pp. 590-596, 2011.

[18] C. Fornaini, G. Lagori, E. Merigo et al., "Analysis of shade, temperature and hydrogen peroxide concentration during dental bleaching: in vitro study with the KTP and diode lasers," Lasers in Medical Science, vol. 28, no. 1, pp. 1-6, 2013.

[19] R. B. T. Price, M. Sedarousy, and G. S. Hiltz, "The pH of tooth-whitening products," Journal of the Canadian Dental Association, vol. 66, no. 8, pp. 421-426, 2000.

[20] T. Attin, A. M. Kielbassa, M. Schwanenberg, and E. Hellwig, "Effect of fluoride treatment on remineralization of bleached enamel," Journal of Oral Rehabilitation, vol. 24, no. 4, pp. 282286, 1997. 


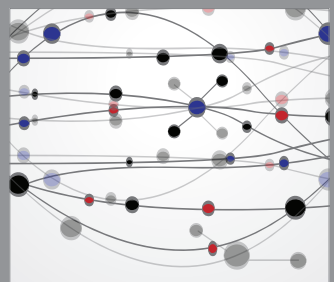

The Scientific World Journal
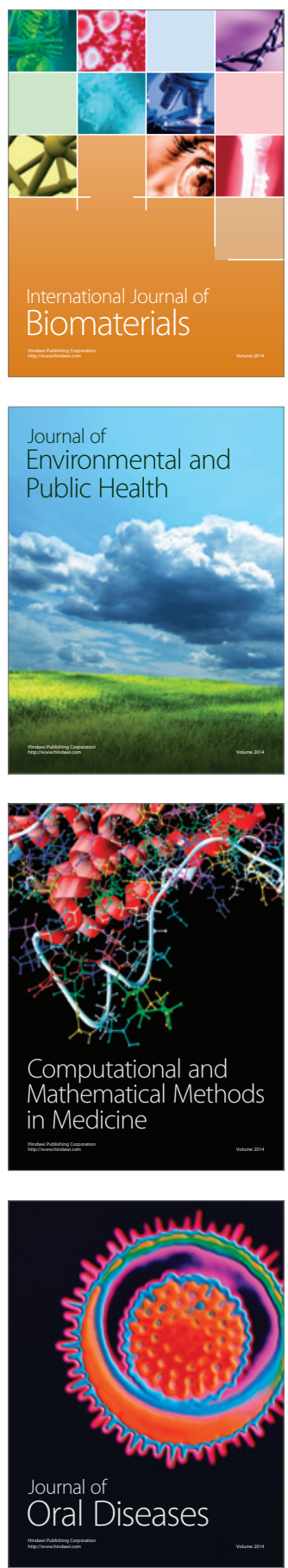
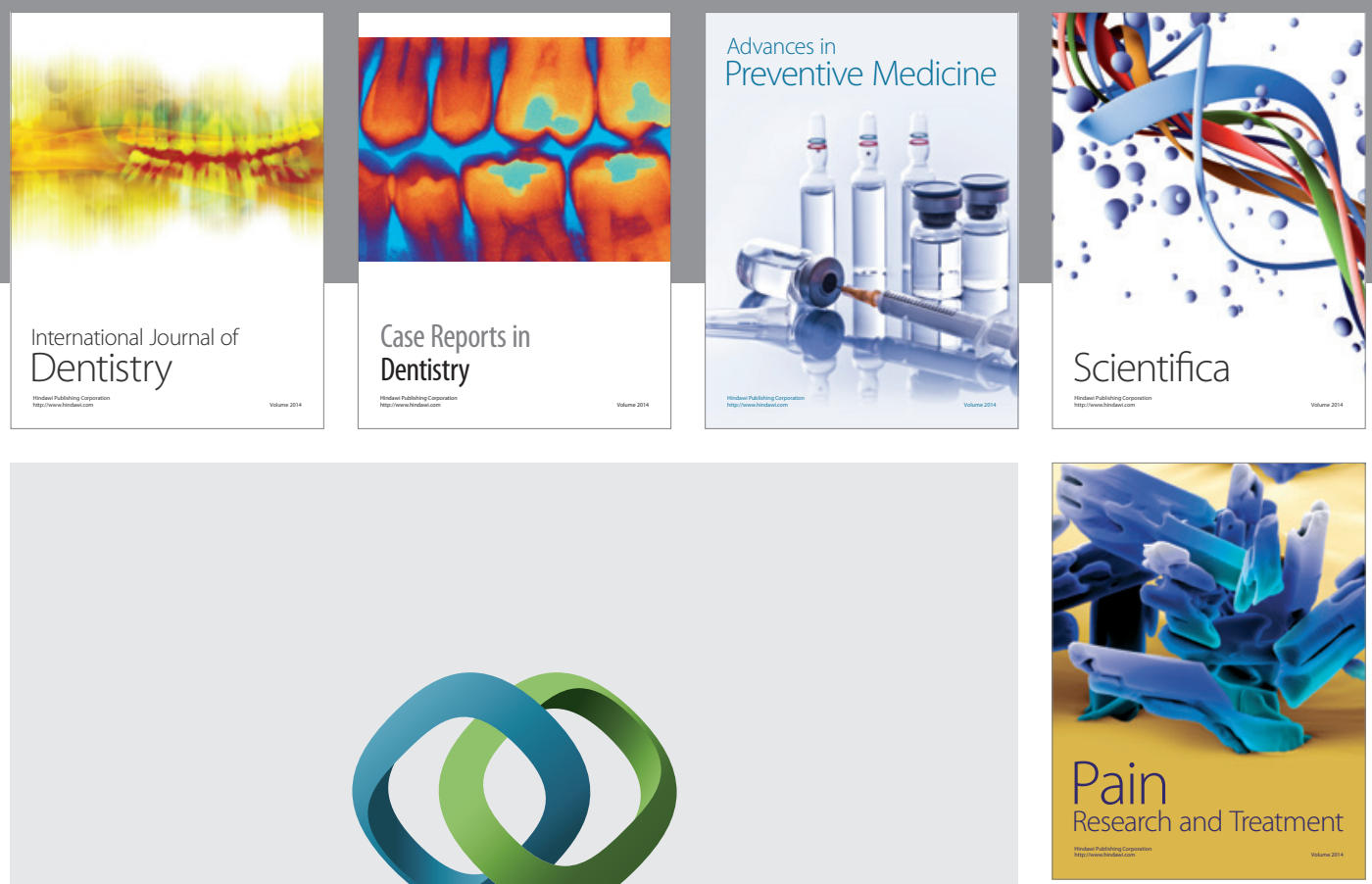

\section{Hindawi}

Submit your manuscripts at

http://www.hindawi.com
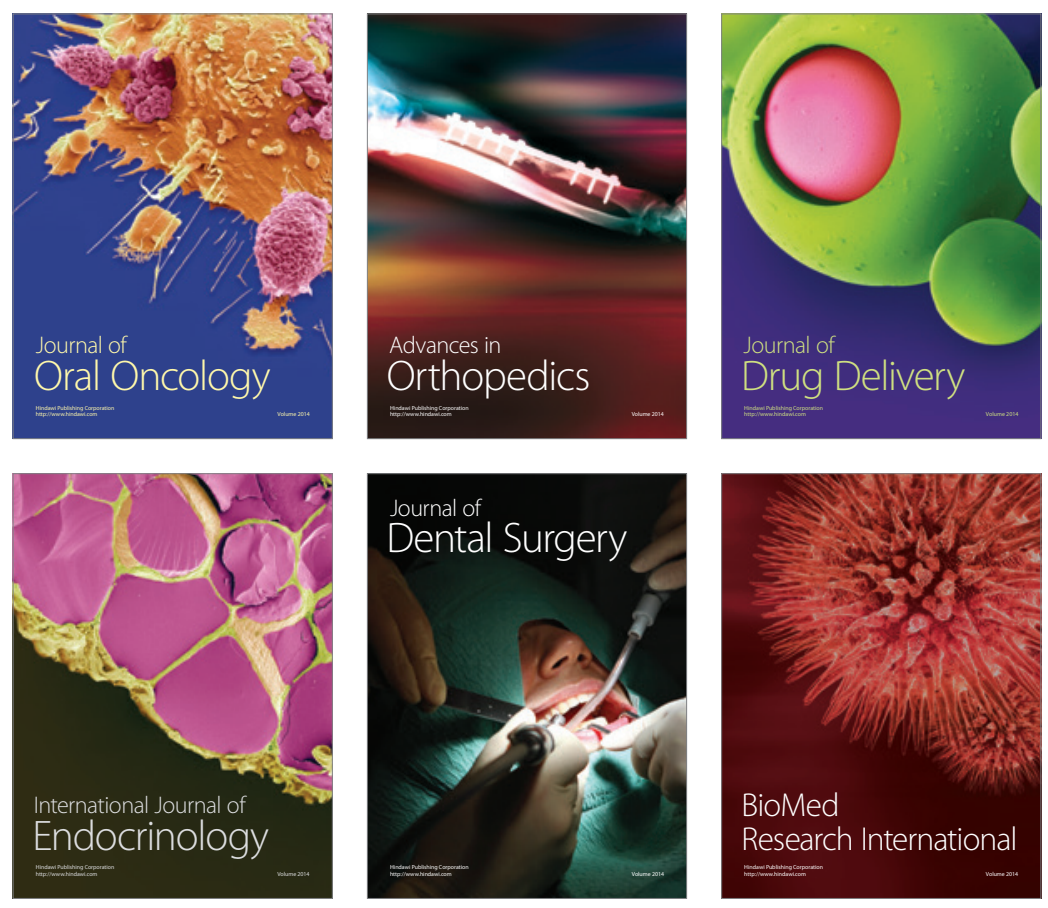

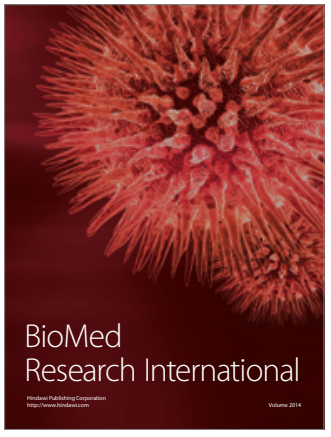

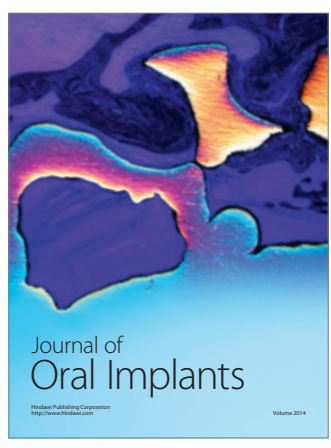
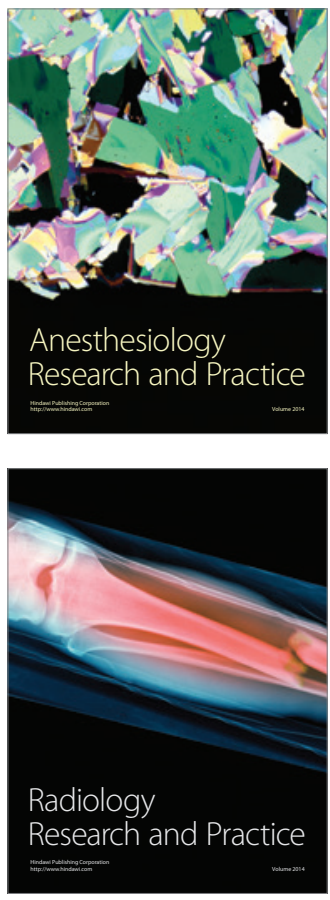